\title{
Quality of Life and Performing Acupuncture on 150 Patients Suffering From Chronic Pains: A Randomized and Intervention Study Before and After Performing
}

\author{
Tahereh Fathi Najafi ${ }^{1, *}$, Mahshid Hejazi ${ }^{2}$, Mojtaba Meshkat ${ }^{1}$, Soheila Hajibabakashani ${ }^{1}$ \\ ${ }^{1}$ Department of Midwifery in Medical University, Mashhad Branch, Islamic Azad University, Mashhad, IR Iran \\ ${ }^{2}$ Department of Foreign Languages, Mashhad Branch, Islamic Azad University, Mashhad, IR Iran \\ * Corresponding Author: Tahereh Fathi Najafi, Department of Midwifery in Medical University, Mashhad Branch, Islamic Azad University, Mashhad, IR Iran \\ .Tel:+98-5118687122, Fax: +98-5118687122, E-mail:fathi_midwife@yahoo.com
}

Keywords: Acupuncture; Quality of Life; Pain

\section{Dear Editor,}

Pain is the commonest complain of human being. If it becomes chronic it affects all the dimensions of life quality. There are many ways to relief pain but some of them have disadvantages that make not well feeling for patients. Currently, people have been attracted to complementary treatments and one of the main ways to cure chronic pain is acupuncture (1-4). Two extensive studies in Germany have shown the effects of acupuncture on the life quality of the patients suffering from chronic diseases 1.According to WHO the best definition of quality of life is: "understanding one's situation in life based on the culture, the evaluative system with which one is living, the goals, expectations, standards, and priorities (5). The purpose of this study is to examine the effect of acupuncture on the quality of life on 150 patients who suffered from chronic pain. This study is a descriptive and intervention type before and after of intervention. All patients were suffering from arthritis pain, migraine backaches, muscular spasms, pain in the neck, and in the knee. The patients went through acupuncture for $8-10$ sessions and either once or two times a week. The number and the place of needles were $8-12$ for each patient which were located on the right place and acupuncture was done by Dr Sadr Nabavi who has a specialist in acupuncture. Data analysis was done by SPSS software. T -test and variance analysis was done at the meaningful level of 5\%.The life quality questionnaire (WHOQOL) of the World Health Organization included have 4 domains. 77.3\% i.e. of the participants were women. $22.7 \%$ i.e. were men. The highest age range were between $41-50$ (28\%) and the lowest were between $71-75$ (4.7\%).46\% of the pain was related to backaches, rheumatoid arthritis $16.7 \%$, migraine $14.7 \%$ and the smallest rate goes to other disorders like pain in the neck 9.3\%.). After 3 months of acupuncture, it was revealed that Life quality is changed $(\mathrm{P}=0.0001$ and $\mathrm{P}=0.0001$ respectively) in Environmental and Physical domains in women. All domains in quality of life don't show a significant difference in men (Table 1). The rate of Physical domain increases in the patients who are over 60 years old and under 31 i.e. $(\mathrm{P}=0.004$ vs. $\mathrm{P}=0.174)$. Psychological domain doesn't difference before and after acupuncture in different age groups. $(\mathrm{P}=0.2$ to $\mathrm{P}=0.8$ for all age groups $)$ (Table 1).

Our study revealed that the Physical and Environmental domains of women suffering from muscular -skeletal diseases are better than before acupuncturing. (respectively $\mathrm{P}=0.0001, \mathrm{P}=0.0001$ ), while psychological and social doesn't show it.

-Article type: Letter; Received: 23 Dec 2011, Revised: 18 May 2012, Accepted: 28 May 2012; DOI:10.5812/ircmj.1411

DPlease cite this paper as:

Fathi Najafi T, Hejazi M, Meshkat M, Hajibabakashani S, Quality of Life and Performing Acupuncture on 150 Patients Suffering From Chronic Pains: A Randomized and Intervention Study Before and After Performing. Iran Red Cres Med J. 2013; 15(3): 269-71. DOI: 10.5812/ircmj.1411 


\begin{tabular}{|c|c|c|c|c|}
\hline Variant & Age, y (Less) & Age, $y$ (Most) & Age, $y$, Mean \pm SD & P value \\
\hline \multicolumn{5}{|c|}{ Male } \\
\hline Physical & & & & 0.068 \\
\hline Before & 18 & 68 & $52.3 \pm 10.9$ & \\
\hline After & 39 & 75 & $54.9 \pm 8.5$ & \\
\hline Psychological & & & & 0.055 \\
\hline Before & 25 & 75 & $53.1 \pm 10.2$ & \\
\hline After & 29 & 71 & $50.6 \pm 7.5$ & \\
\hline Social & & & & 0.915 \\
\hline Before & 0 & 100 & $56.6 \pm 25.9$ & \\
\hline After & 17 & 92 & $56.9 \pm 17.7$ & \\
\hline Environmental & & & & 0.091 \\
\hline Before & 31 & 91 & $59.7 \pm 15.6$ & \\
\hline After & 38 & 91 & $62.1 \pm 13.0$ & 0.525 \\
\hline \multicolumn{5}{|l|}{ Total } \\
\hline Before & 31 & 80 & $55.4 \pm 12.2$ & \\
\hline After & 38 & 70 & $56.1 \pm 8.3$ & \\
\hline \multicolumn{5}{|c|}{ Female } \\
\hline Physical & & & & 0.001 \\
\hline Before & 7 & 82 & $51.5 \pm 15.6$ & \\
\hline After & 11 & 82 & $54.4 \pm 10.9$ & \\
\hline Psychological & & & & 0.737 \\
\hline Before & 25 & 75 & $52.4 \pm 11.7$ & \\
\hline After & 33 & 75 & $52.2 \pm 8.6$ & \\
\hline Social & & & & 0.063 \\
\hline Before & 0 & 100 & $57.0 \pm 25.4$ & \\
\hline After & 17 & 100 & $59.7 \pm 21.2$ & \\
\hline Environmental & & & & 0.0001 \\
\hline Before & 22 & 97 & $60.9 \pm 17.3$ & \\
\hline After & 22 & 97 & $63.8 \pm 15.2$ & \\
\hline Total & & & & 0.002 \\
\hline Before & 20 & 89 & $55.4 \pm 14.0$ & \\
\hline After & 30 & 88 & $57.5 \pm 11.1$ & \\
\hline
\end{tabular}

(respectively $\mathrm{P}=0.083, \mathrm{P}=0.208$ )."Wang, Hunter and Hoseiabadi and their colleagues" showed a meaningful difference in Physical and Environmental domains (6-8). In this study the best life quality improvement in Physical domain has been seen in women. Uthaikhup and Plank also confirm our findings $(9,10)$. All domains don't show difference in before and after acupuncture in men it may be depend on their attitude to complementary medicine in Iran. However, acupuncture can be considered as a useful way of treatment for the patients who suffer from chronic muscular-skeletal diseases.

\section{Acknowledgements}

The researchers would like to thank all the patients who truthfully collaborated with us during the treatment procedure and Dr Reza Sadr-e- Nabavi who let us work in his clinic. The source funding of this survey was paid by the authors, because they liked doing of acupuncture in their city for first time.

\section{Authors' Contribution}

None declared. 


\section{Financial Disclosure}

None declared.

\section{Funding Support}

None declared.

\section{References}

1. Cho SH, Kim J. Efficacy of acupuncture in management of premenstrual syndrome: a systematic review. Complement Ther Med.2010;18(2):104-11

2. Stavem K, Rossberg E, Larsson PG. Health-related quality of life in a trial of acupuncture, sham acupuncture and conventional treatment for chronic sinusitis. BMC Res Notes.2008;1:37

3. Vaghela SA, Donnellan CP. Acupuncture for back pain, knee pain and insomnia in transverse myelitis - a case report. Acupunct Med.2008;26(3):188-92

4. van den Berg I, Tan L, van Brero H, Tan KT, Janssens AC, Hunink MG. Health-related quality of life in patients with musculoskel- etal complaints in a general acupuncture practice: an observational study. Acupunct Med.2010;28(3):130-5

5. Bonomi AE, Patrick DL, Bushnell DM, Martin M. Validation of the United States' version of the World Health Organization Quality of Life (WHOQOL) instrument. J Clin Epidemiol.200 0;53(1):1-12

6. Hoseinabadi R, Nourozi K, Poursmail Z, Karimlu M, Maddah Sadat B, Cheraghi MA. The effect of acupressure on quality of sleep in Iranian elderly nursing home residents. Complement Ther Clin Pract.2010;16(2):81-5

7. Hunter RF, McDonough SM, Bradbury I, Liddle SD, Walsh DM, Dhamija S, et al. Exercise and Auricular Acupuncture for Chronic Low-back Pain: A Feasibility Randomized-controlled Trial. Clin J Pain.2012;28(3):259-67

8. Wang C, de Pablo P, Chen X, Schmid C, McAlindon T. Acupuncture for pain relief in patients with rheumatoid arthritis: a systematic review. Arthritis Rheum.2008;59(9):1249-56

9. Plank S, Goodard J. The effectiveness of acupuncture for chronic daily headache: an outcomes study. Mil Med.2009;174(12):1276-81

10. Uthaikhup S, Sterling M, Jull G. Psychological, cognitive and quality of life features in the elderly with chronic headache. Gerontology.2009;55(6):683-93 